\title{
Polymorphisms in MTHFR, MTR, RFC1 and C $\beta S$ genes involved in folate metabolism and thyroid cancer: a case-control study
}

\author{
Tairine Zara-Lopes ${ }^{1}$, Ana Lívia Silva Galbiatti-Dias ${ }^{1}$, Márcia M. Urbanin Castanhole-Nunes ${ }^{1}$, \\ João Armando Padovani-Júnior², José Victor Maniglia², Erika Cristina Pavarino ${ }^{1}$, \\ Eny Maria Goloni-Bertollo ${ }^{1}$
}

\begin{abstract}
${ }^{1}$ Genetics and Molecular Biology Research Unit - UPGEM, Molecular Biology Department, São José do Rio Preto Medical School - FAMERP, São Paulo, Brazil ${ }^{2}$ Otorhinolaryngology and Head and Neck Surgery Department, São José do Rio Preto Medical School - FAMERP, São Paulo, Brazil
\end{abstract}

Submitted: 13 January 2017

Accepted: 15 April 2017

Arch Med Sci 2019; 15, 2: 522-530

DOI: https://doi.org/10.5114/aoms.2018.73091

Copyright (c) 2019 Termedia \& Banach

\section{Abstract}

Introduction: Polymorphisms in genes coding enzymes involved in folate metabolism may cause alterations in this metabolic pathway and contribute to carcinogenesis, because folate is essential for DNA synthesis, methylation and repair. The objective of this study was to investigate the association of MTHFR 677C $>$ T (rs1801133), MTR 2756A>G (rs1805087), RFC1 80A $>\mathrm{G}$ (rs1051266) and CBS 844ins(68) (no rs\#) polymorphisms and thyroid cancer development. The association of these polymorphisms with demographic risk factors and clinical histopathological parameters was also evaluated.

Material and methods: The study is a case-control analysis with a total of 462 individuals (151 patients and 311 controls). Polymerase chain reaction-restriction fragment length polymorphism technique was used for genotyping. The $\chi^{2}$ and multiple logistic regression were utilized for statistical analysis.

Results: The polymorphisms analysis revealed an association between the MTHFR $677 \mathrm{C}>\mathrm{T}$ polymorphism $(\mathrm{OR}=2.87,95 \% \mathrm{Cl}: 1.50-5.48, p<0.01$, codominant model), $(\mathrm{OR}=1.76,95 \% \mathrm{Cl}: 1.18-2.64, p<0.01$, dominant model), $(\mathrm{OR}=2.37,95 \% \mathrm{Cl}: 1.28-4.39, p<0.01$, recessive model $)$ and thyroid cancer. RFC1 $80 \mathrm{~A}>\mathrm{G}$ polymorphism also was associated with thyroid cancer under recessive mode of inheritance $(\mathrm{OR}=1.55 ; 95 \% \mathrm{Cl}: 1.02-2.38 ; p=$ 0.04); however, this polymorphism showed Hardy-Weinberg disequilibrium in the control group $\left(\chi^{2}=24.71, p<0.001\right)$. Furthermore, alcohol $(\mathrm{OR}=1.56$, $95 \% \mathrm{Cl}: 1.36-1.89, p<0.01)$ and tobacco consumption $(\mathrm{OR}=1.97,95 \% \mathrm{Cl}$ : $1.28-3.04, p<0.01$ ) were associated with increased risk for thyroid cancer. The MTR 2756A $>$ G polymorphism showed an association with tumor extent $(\mathrm{OR}=2.69,95 \% \mathrm{Cl}: 1.27-5.71, p<0.01)$ and aggressiveness $(\mathrm{OR}=4.51$, $95 \% \mathrm{Cl}: 1.67-12.1, p<0.01)$.

Conclusions: MTHFR $677 \mathrm{C}>\mathrm{T}$ is significantly associated with increased risk for thyroid cancer and MTR 2756A $>\mathrm{G}$ is associated with tumor extent and aggressiveness. In addition, alcohol and tobacco consumption were associated with increased risk of thyroid cancer. These results may contribute to a better prognosis for thyroid cancer.

Key words: genes, genetic polymorphism, thyroid cancer.

\author{
Corresponding author: \\ Eny Maria Goloni-Bertollo \\ Genetics and \\ Molecular Biology \\ Research Unit - UPGEM \\ Molecular Biology \\ Department \\ São José do Rio Preto \\ Medical School \\ Av. Brigadeiro Faria Lima 5416 \\ 15090-000 São Paulo, Brasil \\ E-mail: eny.goloni@famerp.br; \\ tairinezlopes@gmail.com
}




\section{Introduction}

Thyroid cancer is the most common malignancy of the endocrine system. There are four main types: papillary, follicular, medullary and anaplastic. In Brazil in 2018 there were about 9610 new cases of thyroid cancer and this cancer is the eighth most common type in women [1].

Some risk factors were evaluated for thyroid cancer development, such as gender, age, hormonal factors, family history of cancer, alcohol and tobacco consumption and obesity [2, 3]. Moreover, genetic polymorphisms involved in folate metabolism are related to carcinogenesis, which leads to development of several types of cancer [4-6]. However, results in the literature are still controversial. Furthermore, research addressing the folate pathways is limited in thyroid cancer, and further studies are required in this area $[7,8]$.

Folate metabolism is involved in synthesis, methylation and DNA repair, and several genes including methylenetetrahydrofolate reductase (MTHFR), methionine synthase (MTR), reduced folate carrier 1 (RFC1) and cystathionine $\beta$-synthase $(C \beta S)$ regulate this metabolism. The genetic polymorphisms change enzymatic activity, resulting in DNA hypomethylation and genomic instability [9-11].

The RFC1 enzyme is responsible for absorption and intracellular transport of folate, besides transporting 5-MTHFR to the interior of variety cells, being an important determinant of folate intracellularly concentrations. The gene is polymorphic in exon 2, with substitution of adenine for guanine at nucleotide $80 A>G$ (rs 1051266), affecting plasma folate and homocysteine levels [12, 13]. The MTHFR enzyme, encoded by the MTHFR gene, is responsible for the catalysis of the irreversible reaction of 5,10-methylenetetrahydrofolate to 5-methyltetrahydrofolate, which interferes in DNA synthesis and methylation. It supplies a methyl group for methylation of homocysteine, producing methionine [14]. The MTHFR gene presents a substitution of cytosine by thymine at nucleotide 677C>T (rs1801133) that may be associated with carcinogenesis.

The homocysteine remethylation to methionine is catalyzed by MTR enzyme. This reaction is essential to adequately maintain normal methionine and intracellular homocysteine concentrations. The MTR gene presents a transition of adenine to guanine at position $2756 \mathrm{~A}>\mathrm{G}$ (rs1805087). This polymorphism is related to increased homocysteine in the plasma and DNA hypomethylation, thus possibly influencing the risk of cancer [15].

The $C \beta S$ gene encodes cystathionine $\beta$-synthase, which is the central enzyme in the transsulfuration pathway that irreversibly metabolizes homocysteine (removes homocysteine from the methionine) to cystathionine. It is polymorphic in exon 8 with an insertion of 68 base pairs at nucleotide 844ins(68). This polymorphism has been associated with reduction of homocysteine levels and changes in DNA methylation because of low availability of S-adenosylmethionine, the main methyl donor for methylation reactions, and consequently DNA hypomethylation and carcinogenesis may occur [16].

The aims of the present study were to investigate associations between MTHFR 677C $>$ T, MTR 2756A>G, RFC1 80A>G and CBS 844ins(68) polymorphisms and thyroid cancer patients, to compare the results with subjects without cancer, and to evaluate the association of polymorphisms with risk factors (gender, age, alcohol and tobacco consumption, body mass index - BMI) and clinical histopathological parameters.

\section{Material and methods}

\section{Subjects}

This study protocol was approved by the Ethics Research Committee (20187413.8.0000.5415). All individuals who agreed to participate in the study signed an informed consent form. A total of 462 individuals (151 patients and 311 controls) were evaluated in this case-control study. The case group consisted of 151 patients who were diagnosed with thyroid cancer (125 papillary and 26 follicular) at Hospital de Base, São Jose do Rio Preto, Brazil. The definitive diagnosis was made through examining the results of imaging studies, histopathological analysis, and biopsies. The exclusion criteria were patients with other neoplasms. The tumors were classified based on three criteria of the Union of Cancer Control (UICC) 2010 (http: www.uicc.org - accessed in January 2016) - tumor extent (T), presence of regional lymph node involvement $(\mathrm{N})$ and presence of distant metastasis (M). The clinical stage was used to analyze aggressiveness, being stage I and II (non-aggressive); stage III and IV (aggressive). The presence or absence of extrathyroid extension was also evaluated.

The control group included 311 healthy individuals from the Hospital de Base of the city of São Jose do Rio Preto. Individuals were excluded if they had a family history of cancer, other neoplasms, and chronic disease.

\section{Genotyping}

Genomic DNA was extracted from peripheral blood leukocytes by the method described by Miller et al. [17] with modifications. The genotyping of C $\beta S$ 844ins(68) polymorphisms was determined by PCR. The PCR-RFLP assay was used to identify the MTHFR 677C $>T$ (rs1801133), MTR 2756A>G (rs1805087) and RFC1 80A>G (rs1051266) polymorphisms with Hinf I, Hae III and Hha I en- 
zymes, respectively. The resulting fragments were: MTHFR gene (C allele - 198 bp); T allele - 175 bp, 23 bp); MTR gene (A allele - 413 bp, 85 bp; G allele 290 bp, 123 bp, 85 bp); RFC1 gene (A allele 162 bp, 68 bp; G allele - 125 bp, 68 bp, 37 bp); and $C \beta S$ gene (Wild allele - $171 \mathrm{bp}$; polymorphic allele - $239 \mathrm{bp})$.

The genotyping confirmation was accomplished in $10 \%$ of random samples of each group, and we observed $100 \%$ concordance. The primer sequences used for amplification of the region presenting these polymorphisms are described in Table I.

\section{Statistical analysis}

The Hardy-Weinberg equilibrium (HWE) was assessed using the $\chi^{2}$ test (BioEstat 5.4 program) to evaluate the distribution of genotypes in case and control groups. The multiple regression logistic test was performed by the Minitab/Version 14.0 computer program, adjusting for gender (reference: male), age (reference: < 50 years), alcohol consumption (reference: no alcohol consumption), tobacco consumption (reference: nonsmoking), BMI (reference: <24.9), MTHFR 677C >T (reference: genotype CC), MTR 2756A $>\mathrm{G}$ (reference: genotype $\mathrm{AA}), R F C 180 \mathrm{~A}>\mathrm{G}$ (reference: genotype $\mathrm{AA}$ ) and $C \beta S$ 844ins(68) (reference: homozygous without insertion). In this study, we considered smokers those who smoked $>100$ cigarettes in their lifetime and drinkers those who have at least 4 drinks per week. One drink is equivalent to $30 \mathrm{ml}$ of liquor; $102 \mathrm{ml}$ of wine, and $340 \mathrm{ml}$ of beer [18]. Subjects with BMI $\geq 25.0 \mathrm{~kg} / \mathrm{m}^{3}$ were considered obese. The clinical histopathological parameters also were evaluated by multiple logistic regression.
SNPstat online computer program (available: (<http://bioinfo.iconcologia.net/SNPstats $\rangle$ ) was used to analyze the polymorphisms' effect in models (1) codominant (heterozygous versus homozygous wild type and polymorphic homozygous versus homozygous wild type), (2) dominant (heterozygous and polymorphic homozygous versus homozygous wild type), (3) recessive (polymorphic homozygous versus homozygous wild type and heterozygous), (4) overdominant (heterozygous versus homozygous wild type and polymorphic homozygous), (5) additive (weight polymorphic homozygote and heterozygote versus homozygous wild-type).

The results were presented as odds ratio (OR), $95 \%$ confidence interval $(95 \% \mathrm{Cl})$ and a value of $p<0.05$ was considered significant.

\section{Results}

Table II shows the association of MTHFR 677C $>\mathrm{T}$, MTR 2756A $>\mathrm{G}$, RFC1 80A $>\mathrm{G}$ and $C \beta S$ 844ins(68) polymorphisms with thyroid cancer according to genetic models. For MTHFR $677 \mathrm{C}>\mathrm{T}$ polymorphism the association with increased risk was observed for codominant, dominant and recessive models $(p<0.01)$. RFC1 $80 \mathrm{~A}>\mathrm{G}$ polymorphism was associated with thyroid cancer in recessive model $(\mathrm{OR}=1.55 ; 95 \% \mathrm{Cl}$ : 1.02-2.38; $p=0.04$ ). The MTR 2756A $>\mathrm{G}$ and C $\beta S$ 844ins(68) polymorphisms were not associated with thyroid cancer.

The Hardy-Weinberg equilibrium analysis showed that the genotypic frequencies of MTHFR 677C $>$ T, MTR 2756A $>\mathrm{G}$, RFC1 80A $>\mathrm{G}$ and C $\beta S$ 844ins(68) polymorphisms are in equilibrium in the patients (MTHFR 677C $>$ T: $\chi^{2}=1.79, p=0.17$;

Table I. List of primer sequences

\begin{tabular}{|c|c|}
\hline Polymorphism & Sequence of primers \\
\hline \multicolumn{2}{|l|}{ MTHFR 677C >T: } \\
\hline Sense & 5'- TGA AGG AGA AGG TGT CTG CGG GA 3' \\
\hline Antisense & 5'- AGG ACG GTG CGG TGA GAG TG 3' \\
\hline \multicolumn{2}{|l|}{ MTR 2756A>G: } \\
\hline Sense & 5'- CCA GGG TGC CAG GTA TAC AG 3' \\
\hline Antisense & 5'- GCC TTT TAC ACT CCT CAA AAC 3' \\
\hline \multicolumn{2}{|l|}{ RFC1 80A>G: } \\
\hline Sense & 5'- AGT GTC ACC TTC GTC CC 3' \\
\hline Antisense & 5'- TCC CGC GTG AAG TTC TTG 3' \\
\hline \multicolumn{2}{|l|}{$C \beta S$ 844ins (68): } \\
\hline Sense & 5’- GTT GTT AAC GGC GGT ATT GG 3' \\
\hline Antisense & 5'- GTT GTC TGC TCC GTC TGG TT 3' \\
\hline
\end{tabular}




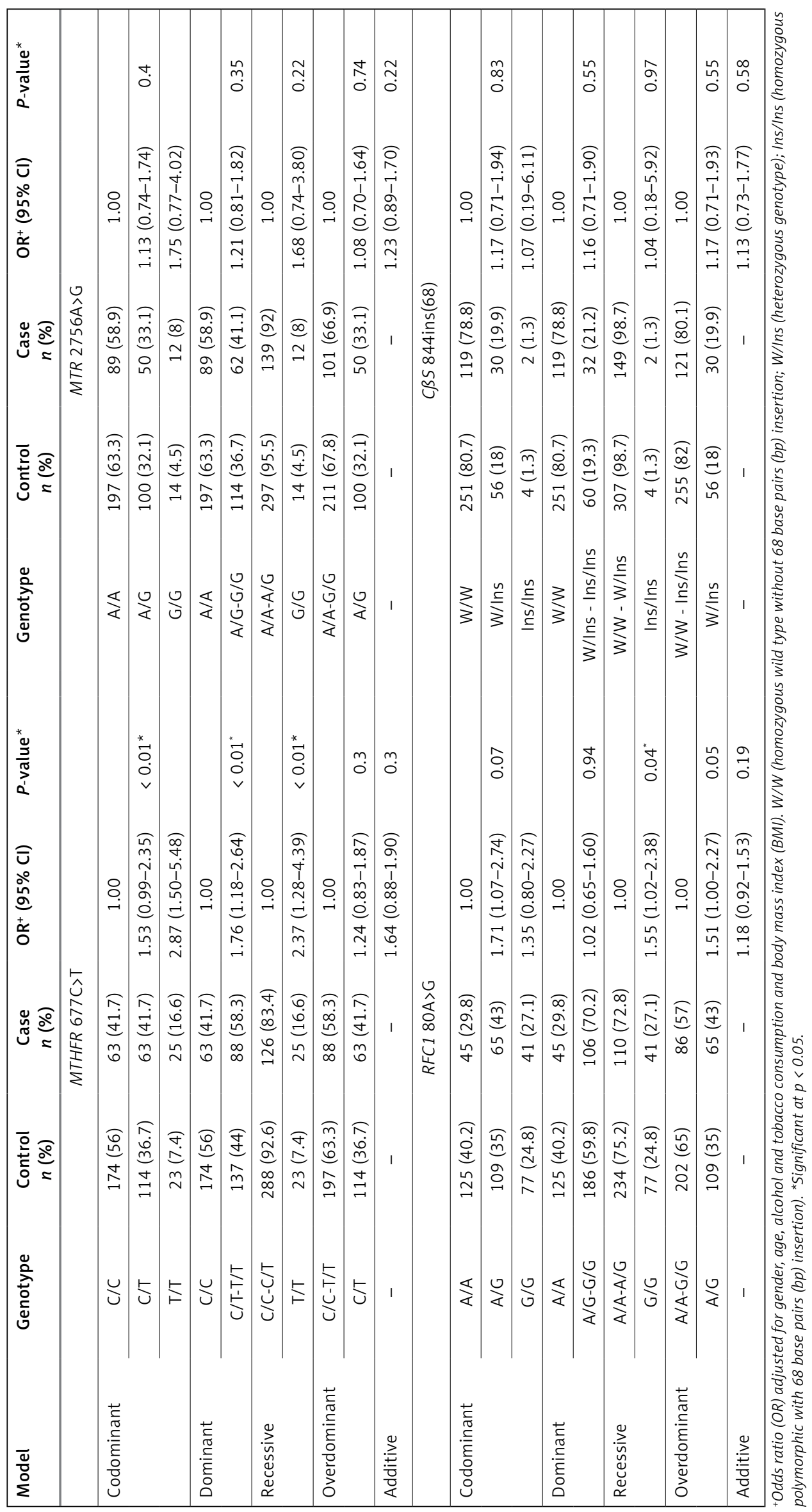


Table III. Distribution of demographic risk factors in patients with thyroid cancer and control individuals

\begin{tabular}{|c|c|c|c|c|}
\hline Variable & $\begin{array}{c}\text { Patients }(n=151) \\
n(\%)\end{array}$ & $\begin{array}{c}\text { Controls }(n=311) \\
n(\%)\end{array}$ & $\mathrm{OR}^{+}(95 \% \mathrm{Cl})$ & $P$-value* \\
\hline \multicolumn{5}{|l|}{ Gender: } \\
\hline Male & $15(9.94)$ & $37(11.90)$ & 1.00 (ref.) & \\
\hline Female & $136(90.06)$ & $274(88.10)$ & $1.07(0.55-2.10)$ & 0.84 \\
\hline \multicolumn{5}{|c|}{ Age [years]: } \\
\hline$<50$ & $73(48.34)$ & $174(55.94)$ & 1.00 (ref.) & \\
\hline$\geq 50$ & $78(51.66)$ & $137(44.66)$ & $1.21(0.80-1.81)$ & 0.36 \\
\hline \multicolumn{5}{|c|}{ Alcohol consumption: } \\
\hline No & $107(70.87)$ & $191(61.42)$ & 1.00 (ref.) & \\
\hline Yes & $44(29.13)$ & $120(38.58)$ & $0.56(0.36-0.89)$ & $<0.001^{*}$ \\
\hline \multicolumn{5}{|c|}{ Tobacco consumption: } \\
\hline No & $89(58.95)$ & $222(71.38)$ & 1.00 (ref.) & \\
\hline Yes & $62(41.05)$ & $89(28.62)$ & $1.97(1.28-3.04)$ & $<0.001^{*}$ \\
\hline \multicolumn{5}{|c|}{ BMI [kg/m²]: } \\
\hline$<25.0$ & $40(26.49)$ & $99(31.83)$ & 1.00 (ref.) & \\
\hline$\geq 25.0$ & $111(73.51)$ & $212(68.17)$ & $1.24(0.79-1.94)$ & 0.35 \\
\hline
\end{tabular}

MTR 2756A $>\mathrm{G}: \chi^{2}=1.66, p=1.19 ; R F C 180 \mathrm{~A}>\mathrm{G}:$ $\chi^{2}=2.89, p=0.08 ; C \beta S$ 844ins $(68): \chi^{2}=0.49$, $p=0.94)$. In the control group, the MTHFR $677 \mathrm{C}>\mathrm{T}$ $\left(\chi^{2}=0.51, p=0.47\right)$, MTR $2756 \mathrm{~A}>\mathrm{G}\left(\chi^{2}=0.08\right.$, $p=0.77)$ and $C \beta S$ 844ins (68) polymorphisms $\left(\chi^{2}\right.$ $=0.18, p=0.66)$ were in equilibrium. For the RFC1 $80 \mathrm{~A}>\mathrm{G}$ polymorphisms the control group showed disequilibrium $\left(\chi^{2}=24.71, p<0.001\right)$.

The multiple logistic regression analysis (adjusted for gender, age, alcohol and tobacco consumption, BMI and polymorphisms) showed that alcohol consumption $(\mathrm{OR}=1.56 ; 95 \% \mathrm{Cl}: 1.36-1.89$; $p<0.001)$ and tobacco consumption ( $\mathrm{OR}=1.97$; 95\% Cl: $1.28-3.04 ; p<0.001)$ were associated with the disease. However, there was no association between gender $(\mathrm{OR}=1.07 ; 95 \% \mathrm{Cl}: 0.55-2.10 ; p=$ $0.84)$, age $\geq 50$ years $(\mathrm{OR}=1.21 ; 95 \% \mathrm{Cl}: 0.80$ $1.81 ; p=0.36)$, BMI (OR = 1.24; $95 \% \mathrm{Cl}: 0.79-1.94$; $p=0.35)$ and thyroid cancer (Table III).

Regarding clinical histopathological parameters of thyroid cancer, Table IV shows the results for polymorphisms' association analysis with these parameters. The polymorphism MTR 2756A>G is associated with tumor extension ( $O R=2.69$; 95\% Cl: 1.27-5.71; $p=0.01)$ and aggressiveness $(\mathrm{OR}=4.51 ; 95 \% \mathrm{Cl}: 1.67-12.1 ; p=0.01)$. The other polymorphisms showed no association with tumor extent $(\mathrm{T})$, regional lymph node involvement (N) and aggressiveness (Table IV). There was no association between extrathyroid extension and analyzed polymorphisms (Table V). Analyses of the clinical histopathological parameters were performed in the dominant model.

\section{Discussion}

In the present study, we evaluated the association of MTHFR $677 \mathrm{C}>\mathrm{T}$, MTR 2756A $>\mathrm{G}$, RFC1 $80 A>G$ and $C \beta S$ 844ins(68) polymorphisms involved in folate metabolism in thyroid cancer. The association of these polymorphisms with demographic risk factors and clinical histopathological parameters was also assessed. We found an association of the MTHFR $677 \mathrm{C}>\mathrm{T}$ and $R F C 180 \mathrm{~A}>\mathrm{G}$ polymorphisms and increased risk for thyroid cancer. Alcohol and tobacco consumption were associated with development of this disease.

In addition, we did not observe the HWE in the control group for RFC1 $80 \mathrm{~A}>\mathrm{G}$ polymorphism; thus these results should be interpreted with caution, because case-control studies assume the existence of HWE equilibrium at least in controls. The observed HWE disequilibrium may be due to random selection samples, model, and disease complexity [19].

Alterations in folate can be associated with polymorphisms. The synthesis of purines and pyrimidine, DNA methylation and repair is directly affected, because folate is a relevant precursor substance for normal cell metabolism. Methylation, in turn, is responsible for gene expression 


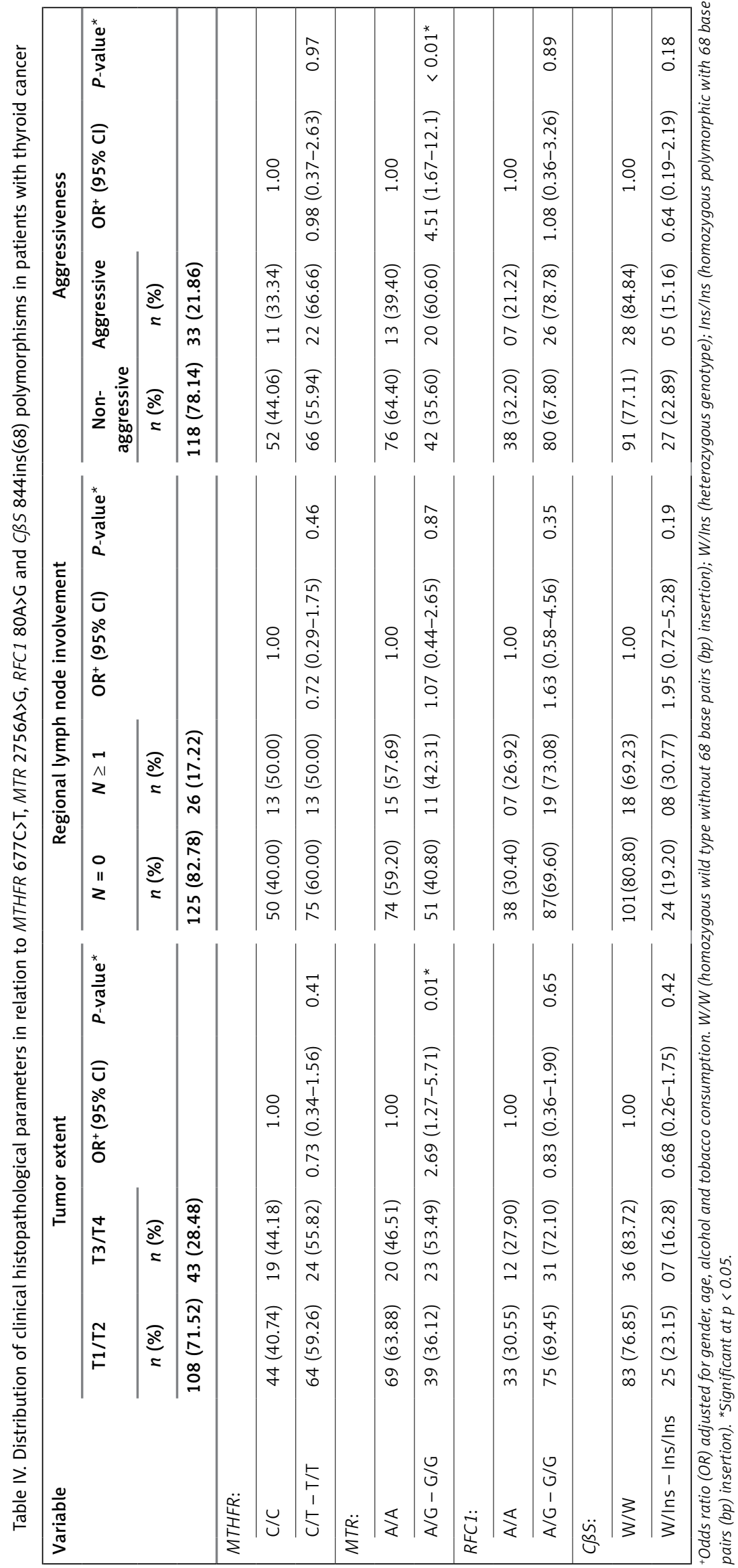


Table V. Association between MTHFR 677C $>$ T, MTR 2756A>G, RFC1 80A $>\mathrm{G}$ and $C \beta S$ 844ins(68) polymorphisms and extrathyroid extension

\begin{tabular}{|c|c|c|c|c|}
\hline Variable & $\begin{array}{c}\text { Absence } \\
n(\%)\end{array}$ & $\begin{array}{c}\text { Presence } \\
n(\%)\end{array}$ & $\mathrm{OR}^{+}(95 \% \mathrm{Cl})$ & $P$-value * \\
\hline \multicolumn{5}{|l|}{ MTHFR 677C >T: } \\
\hline $\mathrm{C} / \mathrm{C}$ & $49(41.88)$ & $14(41.17)$ & 1.00 & \\
\hline $\mathrm{C} / \mathrm{T}-\mathrm{T} / \mathrm{T}$ & $68(58.12)$ & $20(58.83)$ & $0.85(0.37-1.94)$ & 0.69 \\
\hline \multicolumn{5}{|l|}{ MTR 2756A>G: } \\
\hline$A / A$ & $72(61.53)$ & $17(50.00)$ & 1.00 & \\
\hline$A / G-G / G$ & $45(38.47)$ & $17(50.00)$ & $1.72(0.77-3.87)$ & 0.18 \\
\hline \multicolumn{5}{|l|}{$R F C 1$ 80A>G: } \\
\hline $\mathrm{A} / \mathrm{A}$ & $37(31.62)$ & $08(23.52)$ & 1.00 & \\
\hline$A / G-G / G$ & $80(68.38)$ & $26(76.48)$ & $1.43(0.56-3.68)$ & 0.45 \\
\hline \multicolumn{5}{|l|}{ C $\beta S$ 844ins(68): } \\
\hline W/W & 91 (77.77) & $28(82.35)$ & 1.00 & \\
\hline W/Ins - Ins/Ins & $26(22.23)$ & 06 (17.65) & $0.77(0.28-2.15)$ & 0.62 \\
\hline
\end{tabular}

control, chromatin structure and genomic stability $[10,20,21]$.

In the present study, we found an association with MTHFR $677 \mathrm{C}>\mathrm{T}$ and increased risk for thyroid cancer. The studies in the literature are controversial; a study in a Saudi Arabian population reported no association of this genetic variant [22]. Another study performed with papillary carcinoma also no found evidence supporting an association with this polymorphism [21]. On the other hand, a study performed in Turkey involving 60 cases and 50 controls also found increased risk for thyroid cancer [23], as well as the study by Fard-Esfahani et al. [24] conducted with the Iranian population. A meta-analysis on thyroid cancer involving four studies showed a significant association between this cancer and MTHFR $677 C>$ T polymorphism [8]. A Brazilian study involving 100 patients with thyroid cancer and 100 with breast cancer found an increased risk for the 677TT genotype of the MTHFR gene in both types of cancer, which is very common in women worldwide [25].

Our results also revealed increased risk of thyroid cancer for genotype GG of RFC1 polymorphism. However, the association of RFC1 80A>G polymorphism in thyroid cancer has not been analyzed, but was studied in others kinds of cancers. This is the first molecular epidemiological study of this polymorphism in thyroid cancer. In cervical cancer, Di et al. [26] found increased risk for variant $80 G G$ in a Chinese population. Galbiatti et al. [13] found an association with head and neck cancer in males with age $>50$ years. Wang et al. [27] and De Jonge et al. [28] also founded an associa- tion between this polymorphism in gastroesophageal cancer and pediatric acute lymphoblastic leukemia, respectively. On the other hand, studies performed with breast cancer [29] and colorectal cancer [12] did not find an association with this polymorphism.

In this study, the MTR 2756A $>\mathrm{G}$ and $C \beta S$ 844ins(68) polymorphisms were not statistically significant; both had never been studied in thyroid cancer. In breast cancer, two studies did not find an association with this polymorphism [11, 20]. Zhou et al. [30] also did not find increased risk for colorectal cancer. In a meta-analysis Zhao et al. [31] showed no association with MTR 2756A>G polymorphism and digestive system cancer development, unlike a case-control study performed with a Brazilian population that found an association of MTR 2756A>G polymorphism and head and neck cancer [32]. The MTR 2756A $>$ G polymorphism is with the elevation of homocysteine level and DNA hypomethylation due to decreased MTR enzyme [33]. Regarding C $\beta S$ 844ins(68), a study with a Mexican population showed increased risk for breast cancer [16], unlike the study with head and neck cancer that did not find an association with this polymorphism [34].

In the present study, alcohol consumption $(\mathrm{OR}=1.56 ; 95 \% \mathrm{Cl}: 1.36-1.89 ; p<0.001)$ was associated with thyroid cancer development, unlike the study performed by Kabat et al. [35], who found no association between alcohol consumption and thyroid cancer development. Tobacco consumption $(\mathrm{OR}=1.97 ; 95 \% \mathrm{Cl}$ : 1.28-3.04; $p<0.001)$ also was significant in this study. The meta-analysis performed by Jie Ma et al. [36] 
showed a increase of thyroid cancer risk in obesity, regardless of smoking status. Cho et al. [37] observed that smoking may influence susceptibility to thyroid cancer, as our study.

Gender, age $\geq 50$ years and $\mathrm{BMI} \geq 25.0 \mathrm{~kg} / \mathrm{m}^{3}$ were not associated with thyroid cancer. A study performed with a European population showed an association with obesity and thyroid cancer risk only in women [38]. Several others studies also showed increased risk for thyroid cancer in subjects with increased weight [36, 39].

Regarding clinical histopathological parameters, the MTR 2756A $>\mathrm{G}$ polymorphism is associated with tumor extent $(\mathrm{T})(\mathrm{OR}=2.69 ; 95 \% \mathrm{Cl}$ : $1.27-5.71 ; p<0.01)$ and aggressiveness (OR = 4.51; $95 \% \mathrm{Cl}: 1.67-12.1 ; p<0.01)$. In addition, there was not a significant result for regional lymph node involvement $(\mathrm{N})$, extrathyroid extension. Moreover, there are no previous studies in thyroid cancer evaluating these clinical variables and polymorphisms in genes involved in folate metabolism.

Our study may be limited by sample size, and the time of sample collection was relatively short. Studies with polymorphisms involved in the folate pathway and thyroid cancer are still sparse in the literature. MTR 2756A $>\mathrm{G}, C \beta S$ 844ins(68) and RFC1 $80 \mathrm{~A}>\mathrm{G}$ polymorphisms have not yet been analyzed in thyroid cancer; hence the analysis of these molecular biomarkers may be important for a better understanding of thyroid cancer risk.

In conclusion, our data demonstrate the influence of MTHFR 677 C $>$ T polymorphism in thyroid cancer development in the population studied. The results concerning RFC1 polymorphism should be interpreted with caution due to HardyWeinberg disequilibrium in this study. The tumor extent and aggressiveness may be influenced by MTR 2756A>G polymorphism. In addition, alcohol and tobacco consumption are associated with increased risk of this disease. These results may contribute to a better prognosis of thyroid cancer.

\section{Acknowledgments}

This study was supported by Coordination for the Improvement of Higher Education Personnel (CAPES) scholarship, National Scientific and Technological Development Council (CNPq) (Process: 310582/2014-8) and São Paulo Research Foundation (FAPESP) (2010/12930-4, 2012/14781-1).

\section{Conflict of interest}

The authors declare no conflict of interest.

\section{References}

1. INCA (Instituto Nacional do Câncer Estimativa) (2016). Incidência de cãncer no Brasil. Accessed January 24,
2018. Available in: http://www1.inca.gov.br/estimativa/2018/estimativa-2018.pdf.

2. Kitahara CM, Linet MS, Freeman LEB, et al. Cigarette smoking, alcohol intake, and thyroid cancer risk: a pooled analysis of five prospective studies in the United States. Cancer Causes Control 2012; 23: 1615-24.

3. Stansifer KJ, Guynan JF, Wachal BM, Smith RB. Modifiable risk factors and thyroid cancer. Otolaryngol Head Neck Surg 2015; 152: 432-7.

4. Prasad VV, Wilkhoo $\mathrm{H}$. Association of the functional polymorphism C677T in the methylenetetrahydrofolate reductase gene with colorectal, thyroid, breast, ovarian, and cervical cancers. Onkologie 2011; 34: 422-6.

5. Huang L, Zhang T, Xie C, et al. SLCO1B1 and SLC19A1 gene variants and irinotecan-induced rapid response and survival: a prospective multicenter pharmacogenetics study of metastatic colorectal cancer. PloS One 2013; 8: e77223.

6. Zhuo X, Song J, Li D, Wu Y, Zhou Q. MTHFR C677T polymorphism interaction with heavy alcohol consumption increases head and neck carcinoma risk. Sci Rep 2015; 5: 10671.

7. Rai V. Folate pathway gene MTHFR C677T polymorphism and risk of lung cancer in Asian populations. Asian Pac J Cancer Prev 2014; 15: 9259-64.

8. Yang YM, Zhang TT, Yuan L, Ren Y. The association between the C677T polymorphism in MTHFR gene and the risk of thyroid cancer: a meta-analysis. Eur Rev Med Pharmacol Sci 2014; 18: 2097-101.

9. Alshatwi AA. Breast cancer risk, dietary intake, and methylenetetrahydrofolate reductase (MTHFR) single nucleotide polymorphisms. Food Chem Toxicol 2010; 48: $1881-5$.

10. Weiner AS, Boyarskikh UA, Voronina EN, et al. Polymorphisms in the folate-metabolizing genes MTR, MTRR, and CBS and breast cancer risk. Cancer Epidemiol 2012; 36: E95-100.

11. Hosseini M. Role of polymorphism of methyltetrahydrofolate homocysteine methyltransferase (MTR) A2756G and breast cancer risk. Pol J Pathol 2013; 64: 191-5.

12. Eklof V, Van Guelpen B, Hultdin J, Johansson I, Hallmans G, Palmqvist R. The reduced folate carrier (RFC1) 80G > A and folate hydrolase 1 (FOLH1) 1561C > T polymorphisms and the risk of colorectal cancer: a nested case-referent study. Scand J Clin Lab Invest 2008; 68: 393-401.

13. Galbiatti AL, Ruiz MT, Pinto DR, et al. A80G polymorphism of reduced folate carrier 1 (RFC1) gene and head and neck squamous cell carcinoma etiology in Brazilian population. Mol Biol Rep 2011; 38: 1071-8.

14. Yin G, Kono S, Toyomura K, et al. Methylenetetrahydrofolate reductase C677T and A1298C polymorphisms and colorectal cancer: the fukuoka colorectal cancer study. Cancer Sci 2004; 95: 908-13.

15. Jiang-Hua Q, De Chuang J, Zhen-Duo L, Shu-de C, Zhenzhen $\mathrm{L}$. Association of methylenetetrahydrofolate reductase and methionine synthase polymorphisms with breast cancer risk and interaction with folate, vitamin B-6, and vitamin B-12 intakes. Tumour Biol 2014; 35 : 1895-901.

16. Gallegos-Arreola MP, Figuera-Villanueva LE, RamosSilva A, et al. The association between the 844ins68 polymorphism in the CBS gene and breast cancer. Arch Med Sci 2014; 10: 1214-24.

17. Miller SA, Dykes DD, Polesky HF. A simple salting out procedure for extracting DNA from human nucleated cells. Nucleic Acids Res 1988; 16: 1215. 
18. Ahrendt SA, Chow JT, Yang SC, et al. Alcohol consumption and cigarette smoking increase the frequency of p53 mutations in non-small cell lung cancer. Cancer Res 2000; 60: 3155-9.

19. Wittke-Thompson JK, Pluzhnikov A, Cox NJ. Rational inferences about departures from Hardy-Weinberg equilibrium. Am J Hum Genet 2005; 76: 967-86.

20. Carvalho Barbosa RdeC, Menezes DC, Freire TF, Sales DC, Alencar VH, Rabenhorst SH. Associations of polymorphisms of folate cycle enzymes and risk of breast cancer in a Brazilian population are age dependent. Mol Biol Rep 2012; 39: 4899-907.

21. Kweon SS, Shin MH, Kim HN, Kim SH, Kang HC. Polymorphisms of methylenetetrahydrofolate reductase and glutathione S-transferase are not associated with the risk of papillary thyroid cancer in Korean population. Mol Biol Rep 2014; 41: 3793-9.

22. Siraj AK, Ibrahim M, Al-Rasheed $M$, et al. Polymorphisms of selected xenobiotic genes contribute to the development of papillary thyroid cancer susceptibility in Middle Eastern population. BMC Med Genet 2008; 9: 61.

23. Ozdemir S, Silan F, Hasbek Z, et al. Increased T-allele frequency of $677 \mathrm{C}>\mathrm{T}$ polymorphism in the methylenetet rahydrofolate reductase gene in differentiated thyroid carcinoma. Genet Test Mol Biomarkers 2012; 16: 780-4.

24. Fard-Esfahani P, Fard-Esfahani A, Saidi P, Fayaz S, Mo habati R, Majdi M. An increased risk of differentiated thyroid carcinoma in Iran with the 677C > T homozygous polymorphism in the MTHFR Gene. Cancer Epidemiol 2011; 35: 56-8.

25. Zara-Lopes T, Gimenez-Martins APA, Nascimento Filho CHV, et al. Role of MTHFR C677T and MTR A2756C polymorphisms in thyroid and breast cancer development. Gen Mol Res 2016; 15: doi: 10.4238/gmr.15028222.

26. Di JJ, Wang JT, Ding L, Wang ZM, Gao ES. A case-control study on the association of RFC-1 polymorphism and cervical cancer. Zhonghua Liu Xing Bing Xue Za Zhi 2009; 30: 189-91

27. Wang L, Chen W, Wang J, et al. Reduced folate carrier gene G80A polymorphism is associated with an in creased risk of gastroesophageal cancers in a Chinese population. Eur J Cancer 2006; 42: 3206-11.

28. De Jonge R, Tissing WJE, Hooijberg JH, et al. Polymorphisms in folate-related genes and risk of pediatric acute lymphoblastic leukemia. Blood 2009; 113: 2284-9.

29. Kotsopoulos J, Zhang WW, Zhang S, et al. Polymorphisms in folate metabolizing enzymes and transport proteins and the risk of breast cancer. Breast Cancer Res Treat 2008; 112: 585-93.

30. Zhou D, Mei Q, Luo H, Tang B, Yu P. The polymorphisms in methylenetetrahydrofolate reductase, methionine synthase, methionine synthase reductase, and the risk of colorectal cancer. Int J Biol Sci 2012; 8: 819-30.

31. Zhao Y, Chen Z, Ma Y, et al. Lack of association between methionine synthase $\mathrm{A} 2756 \mathrm{G}$ polymorphism and digestive system cancer risk: evidence from 39327 subjects. PloS One 2013; 8: e61511.

32. Galbiatti AL, Ruiz MT, Biselli-Chicote PM, et al. 5-Methyltetrahydrofolate-homocysteine methyltransferase gene polymorphism (MTR) and risk of head and neck cancer. Braz J Med Biol Res 2010; 43: 445-50.

33. Yu K, Zhang J, Zhang J, et al. Methionine synthase A2756G polymorphism and cancer risk: a meta-analysis. Eur J Hum Genet 2010; 18: 370-8.

34. Galbiatti AL, Ruiz MT, Raposo LS, Maniglia JV, PavarinoBertelli EC, Goloni-Bertollo EM. The association between CBS 844ins68 polymorphism and head and neck squamous cell carcinoma risk - a case-control analysis. Arch Med Sci 2010; 6: 772-9.

35. Kabat GC, Kim MY, Wactawski-Wende J, Rohan TE. Smoking and alcohol consumption in relation to risk of thyroid cancer in postmenopausal women. Cancer Epidemiol 2012; 36: 335-40.

36. Ma J, Huang M, Wang L, Ye W, Tong Y, Wang H. Obesity and risk of thyroid cancer: evidence from a meta-analysis of 21 observational studies. Med Sci Monit 2015; 21: 283-91.

37. Cho YA, Kim J. Thyroid cancer risk and smoking status: a meta-analysis. Cancer Causes Control 2014; 25 1187-95.

38. Rinaldi S, Lise M, Clavel-Chapelon F, et al. Body size and risk of differentiated thyroid carcinomas: findings from the EPIC study. Int J Cancer 2012; 131: E1004-14.

39. Kim HJ, Kim NK, Choi JH, et al. Associations between body mass index and clinico-pathological characteristics of papillary thyroid cancer. Clin Endocrinol 2013; 78: 134-40. 